\title{
Uma visita aos índios do rio Trombetas*
}

Gottfried Polykrates

POLYKRATES, G. Uma visita aos índios do rio Trombetas. R. Museu Arq. Etn. 37: 47-56, 2021.

Resumo: Um dos produtos de um mapeamento etnográfico feito por Polykrates ao longo do rio Trombetas e afluentes, esse texto, de 1957, trata de alguns aspectos da vida e cultura do povo Katxuyana, à época identificado como Kashuiéna, e autodenominado Uarikiana. Além de abordar o modo de vida e cultura material do povo visitado, Polykrates descreve a festa Kurínguri, a qual pôde presenciar durante sua visita a uma das aldeias no rio Cachorro. Neste relato de viagem, também são mencionados os seguintes povos como então habitantes do rio Trombetas e vizinhanças: Kahiána (ou Kahianá), Tunajéna e Pianacotó.

Palavras-chave: Índios; Trombetas; Katxuyana; Kahyana; Festas.

E m 1957, durante expedição ao Brasil feita em companhia do sr. Christen Søderberg, de Copenhague, para a realização de um mapeamento etnográfico do rio Trombetas, tive a oportunidade de passar alguns meses entre os índios Kashuiéna. Esses não haviam sido até então descritos na bibliografia etnográfica, apenas mencionados em alguns trabalhos (Coudreau 1900: 73; Frikel 1957: 546), além de três artigos sobre temas diversos (Frikel 1953, 1955; Kruse 1955: 405). Na esperança de ajudar a preencher uma lacuna nos conhecimentos sobre os índios das florestas tropicais da América do Sul, permiti-me publicar algumas observações sobre a cultura dos Kashuiéna.

Os índios Kashuiéna, autodenominados Uaríkiana (uariki é um peixe), podem ser encontrados às margens do rio Cachorro (lat. $1^{\circ} 45^{\prime}$ S., long. $57^{\circ} 20^{\prime}$ O.), do rio Trombetas (lat. $0^{\circ} 13^{\prime}$ S., long. $57^{\circ} 52^{\prime}$ O.) e do igarapé Iaskuri.

* Texto traduzido a partir do original em alemão por Marcelo Victor: Polykrates, G. Ein besuch bei Indianern am Rio Trombetas. Ethnos 3-4: 128147 .
Aparentemente, há também uma aldeia com quatro habitantes no rio Mapuera. Esses grupos estão em frequente contato um com o outro, principalmente em ocasião de festividades religiosas. Os membros da tribo totalizam 62 indivíduos, dos quais 27 vivem à beira do rio Cachorro, 15 às margens do rio Trombetas, em aldeias de 11 e quatro pessoas, e, por fim, 16 vivem às margens do Igarapé Iaskuri. Os dois grupos que habitam as margens do rio Trombetas são chamados pelos outros de Kahiána (na língua kashuiéna, o rio Trombetas chama-se Kahú).

\section{Cultura material}

\section{Agricultura}

Este ofício é praticado de forma semelhante entre a grande maioria das tribos de florestas tropicais: pratica-se uma agricultura de coivara, isto é, a abertura de clareiras na mata nativa, tanto para o cultivo como para qualquer trabalho, função atribuída às mulheres. 
Ocasionalmente apenas, sobretudo quando há a plantação de uma grande área, recebem auxílio dos homens. A disposição das culturas, com exceção da mandioca, é arbitrária. Das plantas e árvores cultivadas, distinguiu-se 17:

1-2: dois tipos de mandioca - a amarga, que recebe o nome manikuré, e a doce, também conhecida sobretudo no Norte do país por macaxeira. Da amarga são feitos um pão, áriha, farinha, e, misturada ao caldo de cana-de-açúcar, compõe uma bebida, kuraí, consumida por eles diariamente. A mandioca doce é comida como batatas. Elas são postas em buracos de aproximadamente $10 \mathrm{~cm}$ de profundidade e a uma distância de 40-50 cm um do outro. 3: batata-doce, parí. 4: bananas, harúru. 5: milho, ónase, muito pouco (sic). 6: mamão, mamája. 7: laranjas; os índios Kashuiéna usam a palavra usada em língua portuguesa. 8: cana-de-açúcar, paranté. 9: abacaxi, menúre. 10: abóbora, martéke. 11-12: dois tipos de cabaça; a grande, totómo, e a pequena, chuchúri. 13-14: dois tipos de algodão, póko e maúru. 15: uma espécie de bromélia denominada iliáua, semelhante ao abacaxizeiro. 16: urucum, onómto. 17: cana-do-rio, práue.

O tabaco, embora consumido por todos, não é cultivado, mas adquirido de fora. É também chamado de tamtaríri. Ele não é inalado. Os compostos para inalação são preparados pelo curandeiro, piáse, a partir de frutos de angico ou paricá (Piptadenia peregrina), morí em Kashuiéna, os quais se assemelham a feijões. Os feijõezinhos são torrados em tachos de argila e moídos até que fiquem bem finos.

\section{Caça e pesca}

A caça é feita com arco e flecha e armas antigas. Os diferentes tipos de flechas são usados de acordo com a caça. O arco, talhado rudemente com um facão e, depois, minuciosamente desbastado com garras de porco do mato, tem comprimento de aproximadamente dois metros.

De kamáraua, uma espécie de trepadeira, é feito um veneno, kamáni, posto na ponta das flechas. Ele, porém, é pouco usado. O uso de kamáni é descrito por Frikel (1953) em mais detalhes.

A maior parte da caça é consumida, com exceção dos cervídeos, kheáu, de cujos fêmures são feitas flautas.

Parte da pesca é feita com arco e flecha, a partir da terra ou de canoas. Pesca-se também com anzóis; esses, porém, não são feitos pela própria tribo.

A pesca com venenos é conhecida, mas não praticada. $O$ veneno é extraído de um arbusto que recebe o nome nakú (em português: timbó-açu, Derris guianensis). Há uma geração, era chamado de kunáni; os Kashuiéna não puderam explicar a razão para a mudança de nome. Nas cachoeiras encontrase um peixe, cána, que não é consumido. Conta-se de dois pajés que os comeram e padeceram até a morte.

\section{Vestuário}

Os homens trajam tiras de algodão, mamí, que passam por entre as pernas e são presas em um largo cinto, feito de casca de árvores. Sob o cinturão, os homens mais velhos usam cordões de algodão presos na cintura, os quais suspendem o pênis. Eles explicam que assim faziam em sua juventude e, portanto, acostumaram-se a isso. Antes, os homens usavam um pequeno cesto para esse fim. 


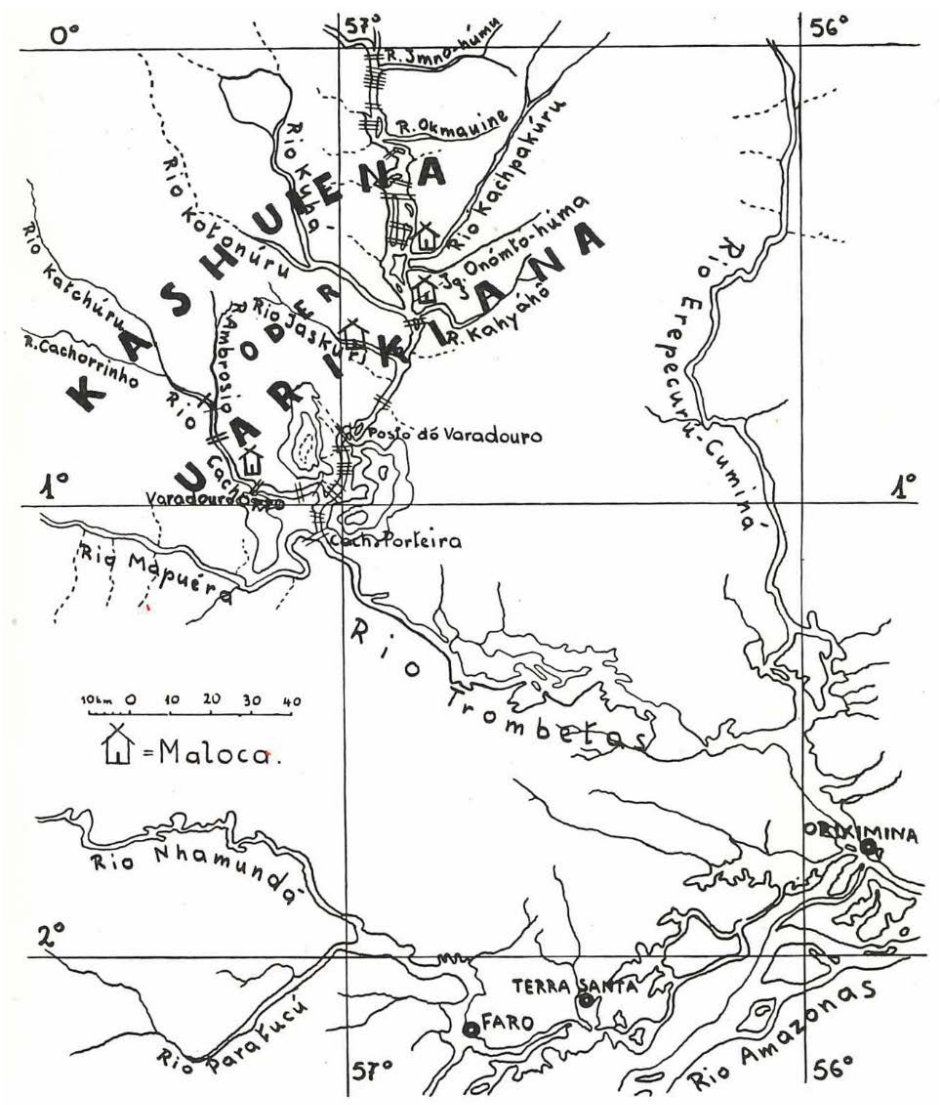

Fig. I. Karte mit Verbreitungsgebiet der Kashuiéna.

Fig. 1. Mapa mostrando a área de distribuição dos Kashuiéna.

Fonte: Elaborada pelo autor (1957).

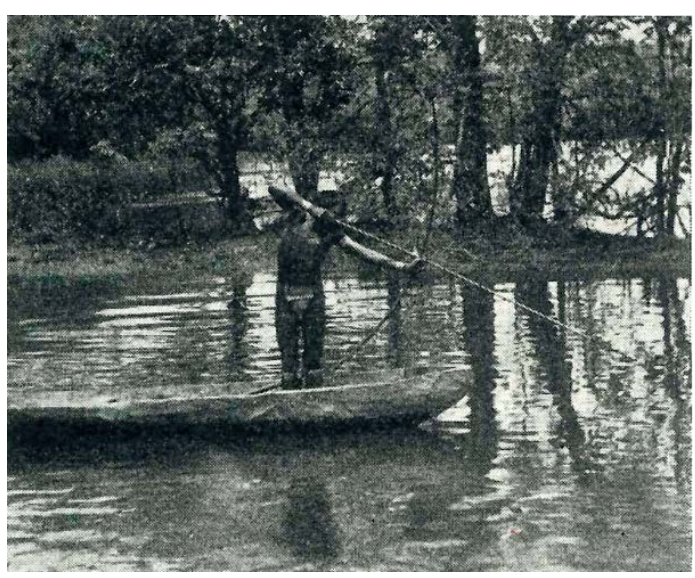

Fig. 2. Os Kashuiéna pescando com arco e flecha.

Fonte: Elaborada pelo autor (1957). 
Em torno dos braços, punhos, calcanhares e logo acima das panturrilhas, são postas tiras de folhas de palmeira, purí, decoradas com pinturas feitas com urucum. Sempre usam também um colar de contas. Dois colares, cruzados sobre o peito, são usados em festas. Um peculiar adorno para a cabeça, feito de penas e um colar de sementes decorado também com penas, são acessórios para danças.
As mulheres trajam um pequeno avental de contas, arranjados em uma armação especialmente feita para esse propósito. Além disso, colares, cordões de contas postos cruzados sobre os ombros, assim como pulseiras e braceletes de contas. Calcanhares e panturrilhas são decorados com cordões de algodão. Antes, as mulheres usavam um traje de casca de árvores.

Já há mais de 100 anos as contas são trazidas das Guianas.

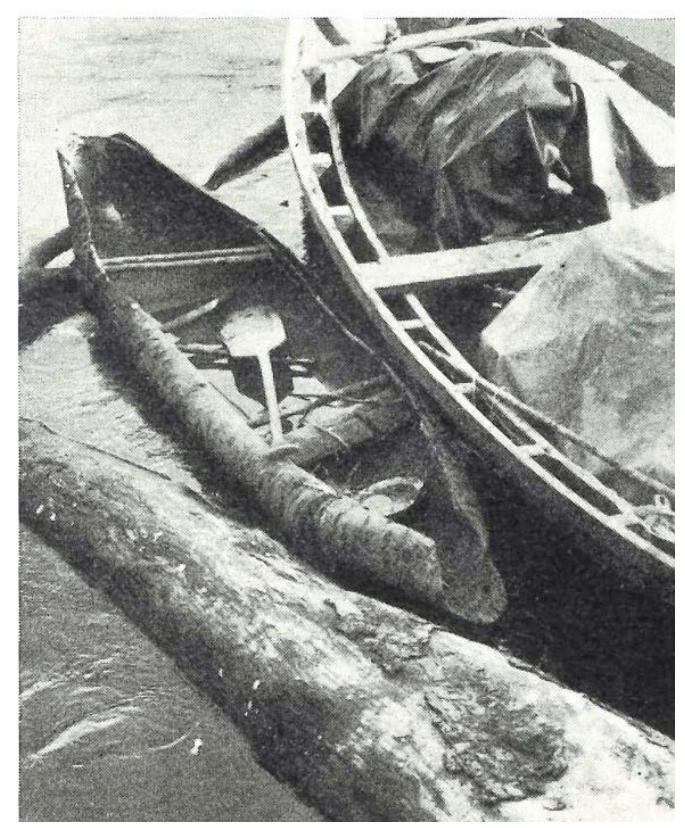

Fig. 3. Barcos feitos de cascas de árvores.

Fonte: Elaborada pelo autor (1957).

\section{Tintas}

São usadas as seguintes tintas: onómto, chinátho e t $\theta$ ého ${ }^{1}$. Onómto, a tinta vermelha extraída do urucum, além de decoração, serve também para a proteção contra os maus espíritos.

Chinátho, uma tinta vermelha obtida dos frutos da trepadeira morókue, é usada na pintura de flechas.
TӨého, também chamada de púrho, é uma tinta preta fabricada de resina. A resina é inflamada e coberta por uma panela com o bojo virado para cima. Nessa panela há um furo para a circulação de ar. $O$ furo é coberto por uma pequena tigela, levando a fumaça a gerar fuligem, a qual, misturada à água, resulta na tinta. Ela serve tanto para a pintura corporal quanto de objetos. 


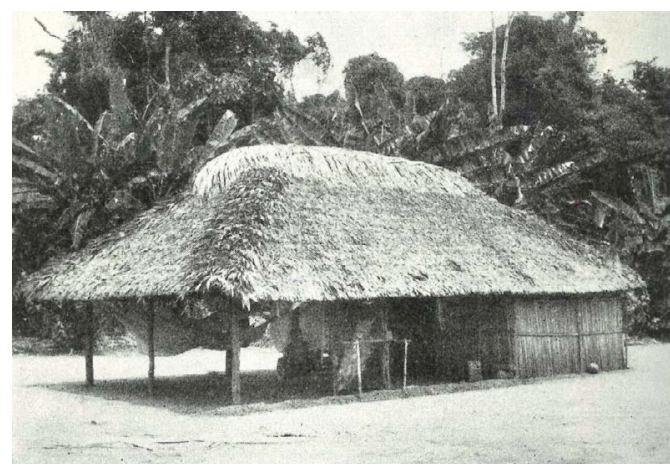

Fig. 4. A casa dos homens.

Fonte: Elaborada pelo autor (1957).

Para as celebrações, o corpo é pintado com motivos que representam peixes, denominados mahájaua. Em português, esses peixes recebem o nome de acari, um nome comum para várias espécies de peixe de água doce, pertencentes à família Loricariidae. Se outros animais também servem de motivos para pintura corporal, não pude distinguir. Foi possível verificar casos de daltonismo entre os homens: eles trocam verde por amarelo e azul por vermelho.

\section{A fabricação de sal}

Os índios conhecem a arte da fabricação de sal de origem vegetal. $\mathrm{O}$ sal é obtido das cinzas resultantes da queima de talos das folhas de palmeira (Attalea sp.). Na língua Kashuiéna, recebe o nome de chúra.

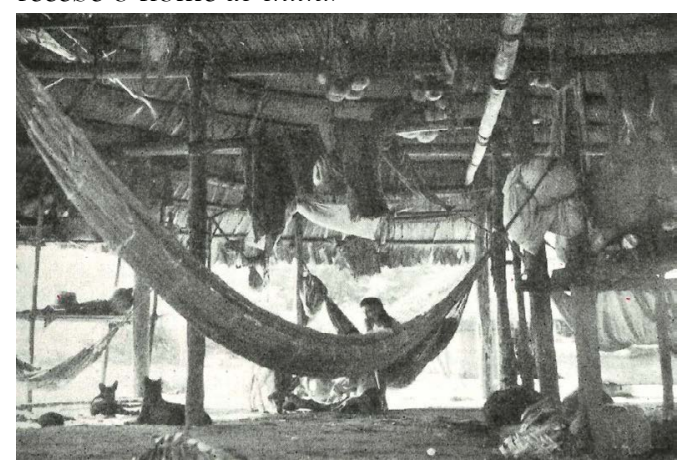

Fig. 5. Interior da casa circular.

Fonte: Elaborada pelo autor (1957).

\section{As moradias (pháta) e seus utensílios}

Como mostram as figuras, são construídas tanto moradias circulares quanto retangulares. As famílias moram nas casas circulares. As casas com bases retangulares servem aos homens durante o dia. À margem do rio Cachorro, três famílias habitavam a casa redonda e, à noite, a casa retangular era usada por uma família para o pernoite. À direita da moradia, há uma plataforma de ripas onde ficam os cães. Eles são usados para a caça. As redes são feitas de algodão. Os cordões da rede são sempre de iliáua.

As panelas são feitas de uma mistura de argila e cinzas de madeira. A árvore que fornece as cinzas chama-se kuehí na língua Kashuiéna e caraipé (Licania scabra) em português.

\section{Comércio e transporte}

Entre os Kashuiéna e os índios Pianacotó, tribo estabelecida ao norte do rio Trombetas, há extensa troca de mercadorias; o deslocamento é sempre feito pelos Kashuiéna. Visto que não há contas para se comprar no rio Amazonas, o comércio com os Pianacotó se faz muito necessário à tribo. Ademais, suas facas, machadinhas, panelas de alumínio e maletas de metal vêm das Guianas. Os cachorros servem como moeda de troca; arcos, redes e urucum, segundo eles, também têm bom valor comercial. Os Kashuiéna não têm ligação com outras tribos; em contrapartida, são comercializadas castanhas, peles de animais e resina com os brasileiros que rondam as matas em torno do rio Cachorro em busca de madeiras de lei e de construção. Em troca, recebem tabaco, pólvora e balas de chumbo.

Tanto pirogas quanto barcos feitos de casca de árvore são usados pela tribo como canoas, kanáua. Os barcos feitos de casca de árvore são usados em pequenas aldeias. Eles logo desaparecerão, pois estão sendo trocados cada vez mais por barcos de feitio neobrasileiro. As canoas são feitas com as cascas de ohíhi e piratái, que em português recebem o nome de jutaí-açu (Hymenea courbaril).

As pirogas são cavadas de uma madeira rosada, que em português é chamada de pau 
rosa, louro-rosa ou louro-cânfora (Ocotea costulata) e em Kashuiéna, irióno.

\section{Âmbito social e religioso}

\section{Organização}

O chefe da tribo, phataitóno, derivado de pháta (casa), é também ao mesmo tempo o curandeiro, piáse, também chamado de muchtúne. As duas funções são hereditárias.

$\mathrm{O}$ aprendizado de um curandeiro dura cerca de um ano. O candidato, um menino de aproximadamente 12 anos, deve, durante esse tempo, ser responsável por sua própria subsistência, vivendo sozinho na mata, e não devendo retornar à aldeia antes do final do treinamento.

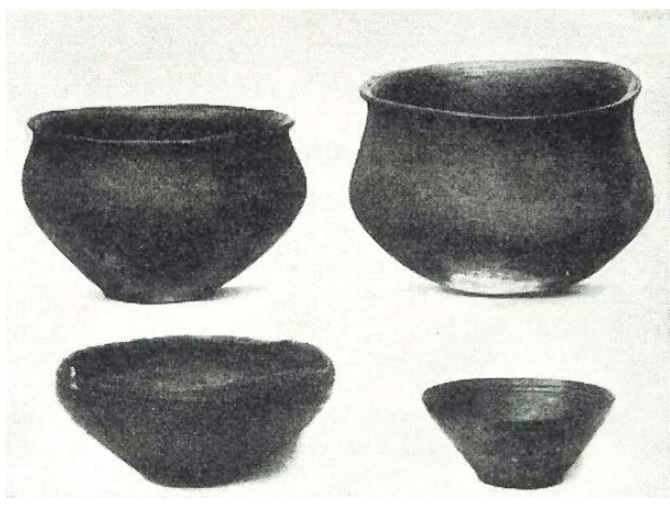

Fig. 6. Louças dos Kashuiéna. Os Kashuiéna de hoje não decoram sua louça. A figura representa os principais tipos de vasilhames da tribo.

Fonte: Elaborada pelo autor (1957).

\section{Divisão do trabalho}

O trabalho dos homens é caçar e pescar, abrir clareiras na floresta, fabricar cestos e cordas de iliáua e colaborar para a limpeza da aldeia.

A plantação e colheita de frutos, a fabricação de redes e o corte de lenha cabe às mulheres, mas também os homens podem tomar parte nessas atividades, caso queiram demonstrar seu cavalheirismo; assim, elas acabam ficando com muito pouco o que fazer.
O trabalho com cerâmica é um privilégio dado apenas às mulheres.

\section{O casamento}

Em geral predomina a monogamia. Há, porém, casos de poligamia: um dos chefes da tribo tem duas esposas; outro também já teve duas. Como preço por sua esposa, o homem deve trabalhar para seus sogros. Depois da primeira menstruação, que passa desapercebida, é dada uma festa à menina, com direito a comida, bebida e música. Não há ritos de puberdade para os meninos. Gêmeos são bemvindos entre os Kashuiéna.

Casos de homossexualidade não devem vir à tona, pois não são tolerados na tribo. Um curandeiro me contou que, em casos assim, a condenação é a morte.

\section{Religião}

Os Kashuiéna creem em uma entidade superior, a qual eles chamam de Purá. Purá tem vários ajudantes. Quando a Terra foi criada, ele criou os índios. Quem criou a Terra, porém, eles não sabem. De acordo com sua crença, o homem foi enviado do sol para a Terra e a mulher foi feita na Terra. Albert Kruse (1955) escreveu de forma mais extensiva sobre Purá.

Apenas os curandeiros podem se comunicar com os espíritos, e em segredo; eles não gostam de falar disso, sobretudo quando outro índio está por perto. Isso ocorre na floresta, e os outros indígenas se mantêm distantes para não atrapalhar a cerimônia. As cerimônias envolvem danças, invocações, música de flauta, fumo de tabaco e inalação de ervas alucinógenas. Nessas cerimônias, eles utilizam um bastão com cabeças de animais esculpidas em madeira, tomómo; um chocalho, maráca; e uma flauta, $\gamma$ uryurí (gr. Gamma $=\gamma$ ). Nenhum outro membro da tribo manuseia esses instrumentos.

Há tomómo com cabeças de quatro animais diferentes. Eles recebem o nome de kurumú 
ou kurujána, totomkukúru, kanúkno e rachkrachk e representam animais e espíritos que os curandeiros convocam e a quem pedem ajuda. O primeiro animal representado é um urubu, que os informa sobre o melhor remédio para o tratamento de doenças.

O próximo animal é a coruja. Ela é convocada à noite. Ela mira os doentes e, com isso, cura-os, caso não haja complicações.

Totomkukúru, em português "Mãe da mata" (espírito da floresta que define o destino da flora e da fauna), protege a aldeia do ataque dos animais.

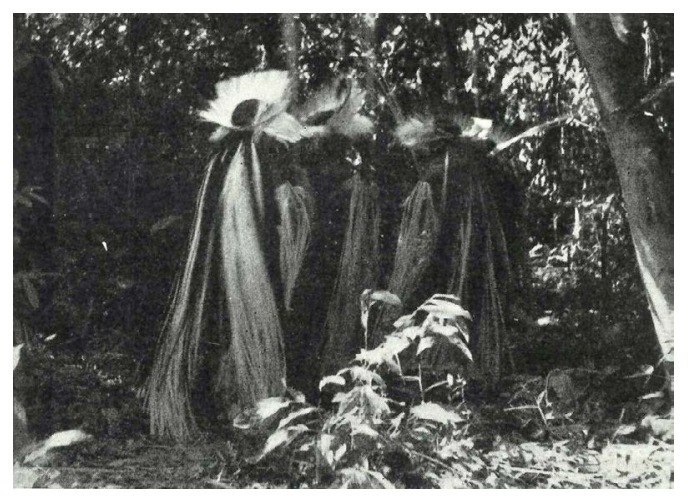

Fig. 7. Dança dos curandeiros.

Fonte: Elaborada pelo autor (1957).

Rachkrachk, o rei dos peixes, envia os peixes aos índios para que eles possam pescá-los.

De acordo com a lenda, havia uma cobra aquática, chamada Marmaruimó, que devorava os canoeiros. Depois que Purá deu-lhes o pau d'arco, eles foram remidos do monstro, pois a cobra não podia digerir a madeira dura.

Sobre os Tunajéna, conta-se que dormem sob a água. É provável que essa história tenha sido transmitida aos Kashuiéna pelos Pianacotós.

Durante uma conversa sobre a religião, dois curandeiros me contaram que o Deus europeu sobre o qual os missionários tanto pregam não é bom, pois ele permite que se faça guerra. Purá, por outro lado, é contra qualquer forma de hostilidade. Eles ouviram dos brasileiros relatos sobre a Guerra Mundial.

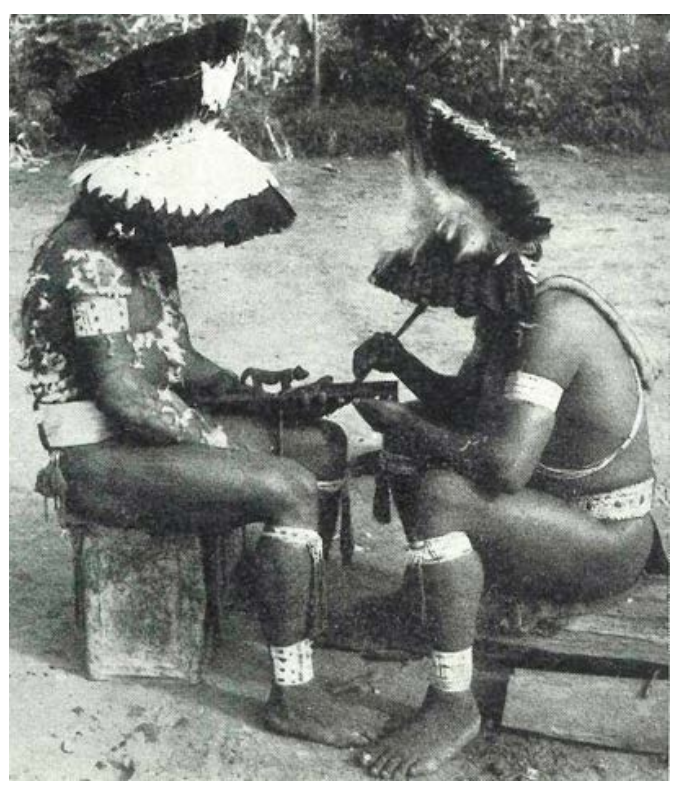

Fig. 8. Inalação de morí (paricá).

Fonte: Elaborada pelo autor (1957).

\section{Medicina}

O reumatismo é tratado da seguinte forma: formigas grandes e vermelhas - não consegui descobrir o nome - são trançadas em folhas de palmeira, de modo que a cabeça fique de um lado e o corpo de outro. Esse trançado é posto sobre o ponto do corpo do paciente de modo que o corpo da formiga toque a pele. De acordo com os curandeiros, o remédio está no corpo da formiga.

\section{Funeral}

Os mortos são enterrados na clareira da aldeia. Seus pertences pessoais ou são afundados no rio, ou lançados à mata. Não há um enterramento secundário. 


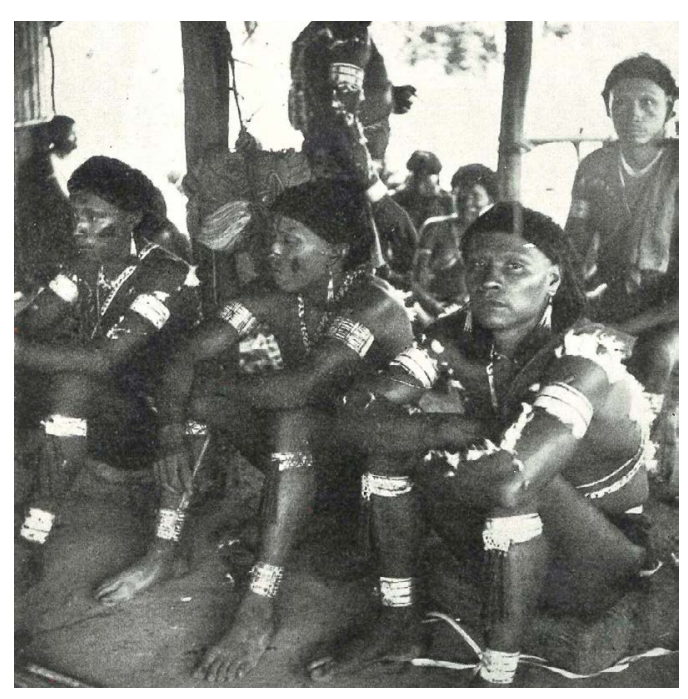

Fig. 9. A festa Kurínguri. Três curandeiros descansando após a cerimônia de inalação de paricá.

Fonte: Elaborada pelo autor (1957).

\section{Festividades}

Há uma série de festas na cultura

Kashuiéna que, de acordo com os indígenas, têm o nome dos meses. Disseram-me que o mês tinha trinta dias, mas só me deram onze nomes. As festas ocorrem ao fim de cada mês. Em cada festa, os espíritos eram bem recompensados; a tribo teria, assim, um bom mês. As exceções são as festas de agosto (uóchku) e setembro (kuringuri). Essas são festas de saúde.

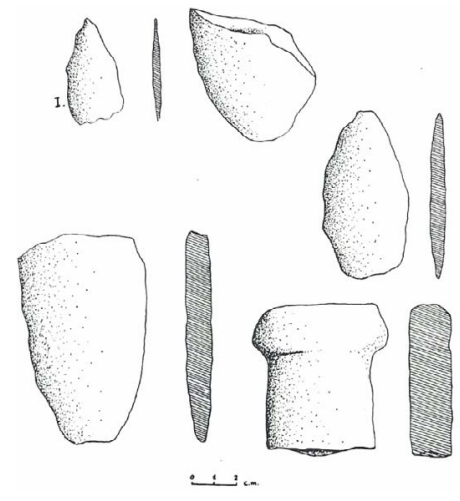

Fig. 10. Artefatos de pedra: fragmentos de machadinha e pontas de flechas (I).

Fonte: Elaborada pelo autor (1957).
A festa foi preparada por muitos dias. Nesse caso especial, foram 13 dias. Todos os dias os indígenas pintavam-se com urucum e ensaiavam passos de danças. Eles limparam a aldeia - dessa tarefa também os homens participaram -, caçaram bastante, pescaram e defumaram as caças. Cana-de-açúcar também foi moída aos montes, para o que eles usavam uma máquina feita por eles mesmos, e conservaram o caldo em barris de barro. Os visitantes chegaram durante os preparativos. Eram índios Kashuiéna (Kahiána) do rio Trombetas, nossos velhos conhecidos que havíamos visitado no mês anterior. Eles vieram para festejar com a tribo.
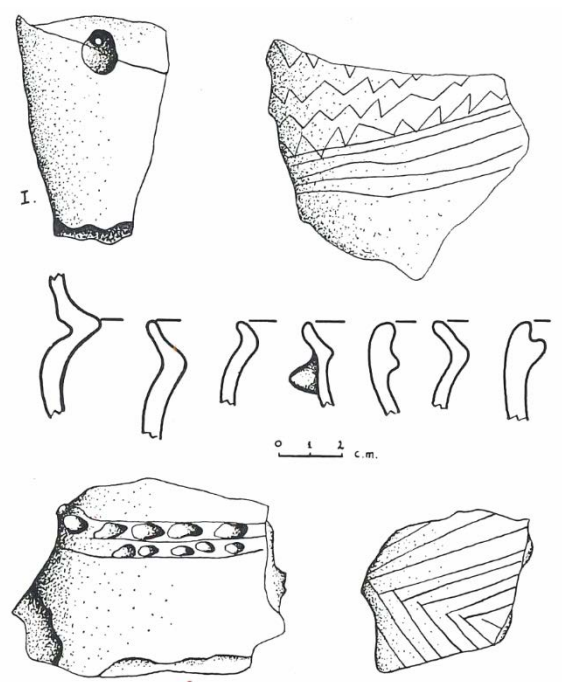

Fig. 11. Cacos de panelas e corte lateral de bordas. (I) Fragmentos de um tripé, estilo Konduri.

Fonte: Elaborada pelo autor (1957).

Os visitantes chegaram depois do pôr do sol. Já ao meio-dia havíamos visto suas canoas, mas eles esperaram na floresta até o pôr do sol, tanto para se enfeitarem para a visita quanto po'is, segundo a tradição deles, só se pode fazer visitas depois do pôr do sol. A comitiva era composta de três homens e suas esposas.

Primeiro vieram os homens. Eles tinham o corpo todo pintado de vermelho e colaram penas brancas sobre a cabeça e o peito. Eles soltaram gritos, tocaram suas flautas um pouco, 
para em seguida voltarem-se à casa dos homens com nova sessão de urros. Lá eles se sentaram com as costas voltadas às cabanas e aos homens da aldeia. Então não foi trocada palavra alguma com os índios da aldeia. As mulheres, pintadas de forma igual e com as plumas coladas na cabeça, dirigiram-se diretamente para a casa redonda, onde, nesse momento, estavam as mulheres da aldeia, com pesos enormes sobre as costas.

Os homens da aldeia já esperavam sentados em um semicírculo em torno de seu chefe, o qual também é chefe de toda a tribo Kashuiéna. Assim, passaram meia hora fumando sem que trocassem uma palavra com os recém-chegados. Então, os três convidados homens foram à casa circular e tomaram lugar no lado de fora. As mulheres conversavam entre si desde o início.

As mulheres da aldeia vieram com um vasilhame em suas mãos que continha uma bebida feita de mandioca e cana-de-açúcar, chamada páie, circundaram os convidados cantando cumprimentos e colocaram o vasilhame no chão. Os convidados tomaram um pouco do líquido e, com uma pena na garganta, provocaram o vômito, para tornar a beber páie e a vomitar novamente. Isso se sucedeu três vezes seguidas. Depois da terceira vez, começaram a comer e a beber água. Depois de lavarem as mãos, tornaram a seus lugares. Isso tudo aconteceu em silêncio profundo. $\mathrm{O}$ vômito deve ser uma tradição; porém, não pude descobrir mais a esse respeito. Passaram então mais uma hora fumando e ainda sem trocar uma palavra com os homens da aldeia. Por fim, duas horas e meia após a chegada, eles se cumprimentaram e conversaram pelo resto da noite.

\section{A festa kurínguri}

Todos os curandeiros - os quatro da aldeia e dois entre os convidados - dirigiram-se à mata para pedir a aprovação dos deuses e dos espíritos para a festa através de uma dança selvagem, que pude presenciar, de urros e de sons de flauta. Assim, a festa começou.
Dançou-se a noite toda, sem interrupção, ao som das flautas dos curandeiros e do cântico monótono dos outros índios. As mulheres participaram por pouco tempo desse ritual. A dança ficou cada vez mais selvagem até cessar com a alvorada. Depois do nascer do sol, as mulheres e as crianças, e também os homens, sentaram-se em duas fileiras. Os curandeiros fizeram os compostos para inalação e todos os homens adultos e jovens com mais de 12 anos fumaram e inalaram esses compostos, sob procedimentos e canções cerimoniais: um curandeiro aproxima-se com sua tabuleta por trás de um membro da tribo, inclina-a sobre a cabeça desse e canta um cântico monótono, enquanto o outro membro mói as sementes de paricá. Ao término, o que leva pouco mais de meia hora, o curandeiro senta-se de frente ao outro índio, segura a tabuleta sob seu nariz e para que aquele inale o pó através de dois canudos, acompanhado pelo cântico do curandeiro.

Passaram o dia assim: o curandeiro dirigiu-se a cada homem e a cada mulher. As mulheres não aspiram o paricá; apenas participam do cerimonial.

Até então, ninguém havia comido ou bebido nada. Também foi proibido se afastar da aldeia. Eles pediram até a nós para não deixarmos a aldeia e, assim, não irritar os espíritos.

Quando do pôr do sol, a cerimônia já havia acabado. Depois de uma breve pausa, os curandeiros vieram banhar todos os presentes, em fila, de cima para baixo, com um líquido feito de água e bananas amassadas, com o nome de harujukúru. Os curandeiros sentaram-se, então, e os demais índios banharam-nos com o líquido. Isso foi feito ao som de risos e gritos. Então, todos foram se banhar no rio e puderam, enfim, comer e beber.

No dia seguinte, um silêncio mortal imperava na aldeia. Todos dormiam. Por meio desse cerimonial, todos estariam protegidos de doenças.

A festa Kurínguri tem, como mencionado anteriormente, o objetivo de espantar os maus espíritos, causadores de doenças. Alguns elementos do cerimonial são comuns à comunidade indígena, que manteve preservada a cultura de seus antepassados. Isso serve tanto para a recepção bastante fria dos convidados 
como para as repentinas reaproximações, logo após o final da cerimônia de recepção. A dança dos espíritos, executada pelos curandeiros no verdadeiro início da festa, foi observada em muitas outras tribos; as cerimônias de inalação se disseminaram em grande parte das tribos sul-americanas, que atribuem ao tabaco e/ou a outras substâncias similares um significado mágico. Para o banho de suco de banana, porém, não há nenhum precedente observado em outra tribo. Essa etapa da festa até agora não foi esclarecida. Certamente, uma elucidação pode ser encontrada na mitologia dos Kashuiéna, a qual ainda não foi suficientemente pesquisada. De toda forma, a festividade Kurínguri dos Kashuiéna é um evento etnográfico, certamente com raízes num passado distante e desconhecido.

\section{Arqueologia}

A aldeia próxima ao rio Cachorro, uma área de 400 x 300 m, é rica em fragmentos, por meio dos quais é possivel reconhecer um estilo Konduri. O mesmo ocorre com artefatos de pedra semelhantes a pontas de flechas que encontrei, ainda que me falte material de comparação para identificálas com segurança como tal. Os depósitos de fragmentos estão, em sua maioria, na superfície ou a uma profundidade de $10-15 \mathrm{~cm}$, o que é típico dos afluentes do rio Amazonas.

POLYKRATES, G. A visit to the people of the Trombetas river. R. Museu Arq. Etn. 37: 47-56, 2021.

Abstract: Resulting from an ethnographic mapping conducted by Polykrates along the Trombetas river and its affluents, this 1957 text deals with some aspects of the life and culture of the Katxuyana people, self-nominated Uarikiana and at the time identified as Kashuiéna. Polykrates also describes the Kurínguri festival, which he witnessed during his visit to one of their villages on the Cachorro river. In this travel report, the following peoples are mentioned as inhabitants of the Trombetas River and neighborhoods: Kahiána (or Kahianá), Tunajéna, and Pianacotó.

Keywords: Indians; Trombetas; Katxuyana; Kahyana; Festivities.

\section{Referências bibliográficas}

Coudreau, O. 1900. Voyage au Trombetas.

A. Lahure, Paris.

Frikel, G. P. 1953. Kamáni. Costumes e preceitos dos índios Kachúyana a respeito do curare. Revista do Museu Paulista 7: 257274.

Frikel, G. P. 1955. Tradições histórico-lendárias dos Kashuyana e Kahuyana. Revista do Museu Paulista 9: 203233.

Frikel, G. P. 1957. Zur linguistisch-ethnologischen Gliederung der Indianerstämme von NordPará (Brasilien) und den anliegenden Gebieten. Anthropos 52: 509563.
Gillin, J. 1948.Tribes of the Guianas and the left Amazon tributaries. In: The Tropical forest tribes. Smithsonian Institution, Washington, Part 5, 799860.

Hilbert, P.P. 1955. A cerâmica arqueológica da região de Oriximiná. Instituto de Antropologia e Etnologia do Pará, Belém.

Kruse, A. 1955. Purá, das höchste Wesen der Arikéna. Anthropos 50: 404416.

Speiser, F. 1926. Im Düster des brasilianischen Urwalds. Strecker und Schröder Verlag, Stuttgart. 